\title{
The Effect of Substrate Microstructure on the Heat-Affected Zone Size in Sn-Zn Alloys Due to Adjoining Ni-Al Reactive Multilayer Foil Reaction
}

\author{
R.J. HOOPER, ${ }^{1}$ D.P. ADAMS, ${ }^{2}$ D. HIRSCHFELD,${ }^{2}$ and M.V. MANUEL (i) $^{1,3}$ \\ 1.-Department of Materials Science and Engineering, University of Florida, Gainesville, \\ FL 32611, USA. 2.-Sandia National Laboratories, 1515 Eubank SE, Albuquerque, NM 87123, \\ USA. 3.-e-mail: mmanuel@mse.ufl.edu
}

\begin{abstract}
The rapid release of energy from reactive multilayer foils can create extreme local temperature gradients near substrate materials. In order to fully exploit the potential of these materials, a better understanding of the interaction between the substrate or filler material and the foil is needed. Specifically, this work investigates how variations in local properties within the substrate (i.e. differences between properties in constituent phases) can affect heat transport into the substrate. This can affect the microstructural evolution observed within the substrate, which may affect the final joint properties. The effect of the initial substrate microstructure on microstructural evolution within the heat-affected zone is evaluated experimentally in two Sn-Zn alloys and numerical techniques are utilized to inform the analysis.
\end{abstract}

Key words: Microstructurally-informed model, heat flow, phase transformation, solder alloys, RMF

\section{INTRODUCTION}

Reactive multilayer foils (RMF) are a class of materials that are being studied due to their ability to act as localized heat sources. ${ }^{1-8}$ This makes them particularly interesting for microelectronics applications where small, dissimilar and often temperature-sensitive components are being joined. ${ }^{9}$ These foils are formed by alternating submicron layers of elements, such as $\mathrm{Ni}$ and $\mathrm{Al}$, that undergo a reaction when energy is input into the foil. This causes mass diffusion to initiate, releasing a highly exothermic latent heat. The reaction is self-sustaining and progresses rapidly.

Due to the small generation and rapid dissipation of heat from RMF reactions, computational methodologies are necessary to inform experimental observations to gain fundamental mechanistic insight, as well as to provide the capability to be predictive when exploring uncommon or new systems. Previous models that have been developed to

(Received April 23, 2015; accepted July 16, 2015;

published online August 5, 2015) describe the heat flow from RMFs into a substrate or filler material for joining applications are limited. ${ }^{4-8}$ They typically lack microstructurally-informed constituent behavior, and, as such, they assume that the substrate structure may be treated as uniform and the properties handled in a continuum fashion. ${ }^{4}$ Although these assumptions are sufficient for fully eutectic, metallic glass, or thin substrate materials, applying these models to materials outside this subset may cause errors in the prediction.

This work seeks to evaluate the effect of initial substrate microstructure on the heat flow and microstructural evolution during and after a RMF reaction. This was accomplished through the study of two experimental substrate Sn-Zn alloys whose mesoscale microstructures are heterogeneous in both morphology and thermal properties. The Sn-Zn alloy system was chosen as a model material for this investigation due to its low melting temperature ${ }^{10}$ and the presence of phases that display material properties, ${ }^{11-13}$ which should highlight the importance of inputting microstructural information into current heat flow models. Attempts to numerically 
model the reactions were made and the predictions are compared to experiments.

\section{EXPERIMENTAL AND NUMERICAL METHODS}

\section{Alloy Preparation and Characterization}

Two Sn-Zn alloys (14 wt.\% $\mathrm{Zn}$ and 50 wt.\% $\mathrm{Zn}$ ) were prepared from $\mathrm{Sn}(99.8 \%$ metal basis) and $\mathrm{Zn}$ shot (99.99\% metal basis) sourced from Alfa Aesar. The alloys were melted in a covered graphite crucible located inside a resistance box furnace at $773 \mathrm{~K}\left(500^{\circ} \mathrm{C}\right)$. After $20 \mathrm{~min}$, the crucible was removed from the furnace and the contents were stirred with a graphite rod. The crucible was then placed back in the furnace for a further 5 min to bring the alloys back to temperature. The melts were then poured into a rectangular copper mold with dimensions of $19 \mathrm{~mm} \times 19 \mathrm{~mm} \times 100 \mathrm{~mm}$ under ambient conditions. Each of the castings was allowed to cool to room temperature before removal from the mold.

For compositional analysis, samples from each alloy were characterized using x-ray fluorescence spectroscopy (XRF) on an EDAX Eagle III machine with an accelerating voltage of $40 \mathrm{kV}$ and a spot size of $90 \mu \mathrm{m}$. Three measurements were taken across each specimen to verify that the composition of the casting was uniform. Transformation temperatures (solidus and liquidus) and enthalpy of fusion ( $\left.\Delta H_{\text {fus }}\right)$ for the alloys were subsequently evaluated using a Perkin Elmer DSC-8000 differential scanning calorimeter (DSC). Specimens (approximately $200 \mathrm{mg}$ each) were heated from $323 \mathrm{~K}$ to $723 \mathrm{~K}$ (50$450^{\circ} \mathrm{C}$ ) at a ramp rate of $20 \mathrm{~K} / \mathrm{min}$. This was repeated at least three times for each of the samples and the information was utilized within the numerical models to account for melting.

Samples were prepared for microstructural analysis using standard metallographic techniques up to a $0.04-\mu \mathrm{m}$ colloidal silica slurry final polish. Microstructural analysis was performed on a Phenom Pro scanning electron microscope (SEM) using the backscattered electron detector to enhance phase contrast in the images.

\section{RMF-Substrate Reaction}

In order to study the effect of RMF reaction on the underlying substrate microstructure, test coupons were sectioned from the castings. The coupons were planed and polished to a $0.04-\mu \mathrm{m}$ finish, with a final thickness of approximately $7.0 \mathrm{~mm}$. This surface treatment was conducted to minimize surface roughness, which can influence the thermal interfacial resistance between layers. ${ }^{14}$ Free-standing $\mathrm{Ni}(\mathrm{V})-\mathrm{Al}$ RMFs were purchased from Indium and had dimensions of $12.7 \mathrm{~mm} \times 12.7 \mathrm{~mm} \times 60.0 \mu \mathrm{m}$. These foils each had a $1-\mu \mathrm{m}$-thick layer of $\mathrm{InCuSil}^{\circledR}$ $\mathrm{ABA}^{\mathrm{TM}}\left(\mathrm{Ag}_{59} \mathrm{Cu}_{27.25} \mathrm{In}_{12.5} \mathrm{Ti}_{1.25}\right)$ on the surface. The reactions were conducted with the foil held between the substrate and a glass slide. The foil, substrate, and glass slide system was held in place with a 200$\mathrm{g}$ weight to minimize foil distortion resulting from the reaction. Additional weight was not used in the experimental set up because previous experiments demonstrated that increased pressure on the reaction setup resulted in material extrusion through fractures in the foil, which made it impossible to properly account for the scale of the heat-affected zone (HAZ) due to material loss. A $20-\mathrm{V}$ DC power supply was used to create an arc between two solid core copper wires to initiate the foil reaction. The samples were then sectioned with a low-speed diamond saw and then prepared for microstructure analysis.

\section{Numerical Modeling}

To elucidate the effects of the substrate microstructure on the size of the HAZ, numerical methods were developed and utilized. First, a onedimensional (1-D) calculation was performed that treated the substrate microstructure as a continuum, which included temperature-dependent thermal properties and substrate phase (i.e. solid or liquid). Conduction from the foil into the substrate was handled using Fourier's law ${ }^{15}$ by assuming that the interface between the materials remained planar and that conduction would dominate other heat transport mechanisms. Additionally, it was assumed that heat loss into the glass slide would be negligible due to the large difference in thermal conductivity between the glass slide and the metal substrate. This approach has been demonstrated to agree with experimental observations. ${ }^{16}$

Heat flow through the substrate was modeled using a finite difference approximation of the 1-D heat equation. A schematic of the calculation space is shown in Fig. 1.

$$
\frac{\partial T}{\partial t}=\alpha\left(\frac{\partial^{2} T}{\partial x^{2}}\right)
$$

The heat evolved from the foil was calculated using Eq. 2. ${ }^{17}$

$$
\Delta H=\Delta H_{0}\left(1-\frac{2 w}{\lambda}\right)
$$

This value is based on the enthalpy of formation for the compound being formed during the reaction $\left(\Delta H_{O}\right)$, the bilayer thickness $(\lambda)$ and the thickness of the intermixed region between two adjoining layers $(w)$ within the RMF. These values were taken to be $1383 \mathrm{~J} / \mathrm{g},{ }^{18} 47.6 \mathrm{~nm}$ (determined experimentally using transmission electron microscopy) and $2.3 \mathrm{~nm},{ }^{4}$ respectively. Using these values, the predicted heat of reaction fell in line with the values published by Indium. The energy value was converted to an initial temperature by assuming that it 


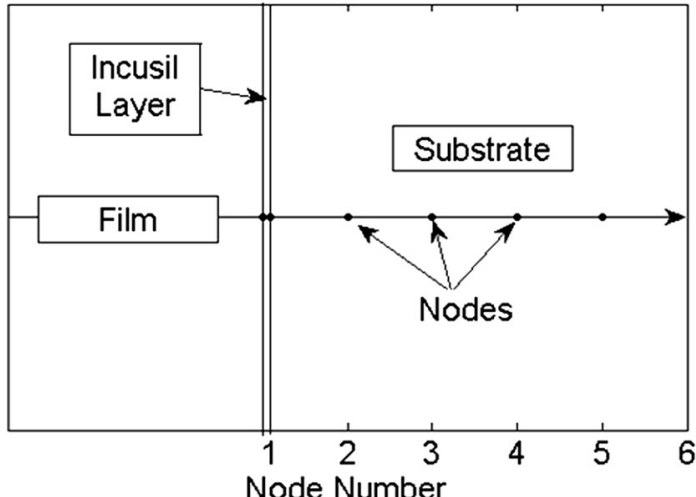

Fig. 1. Schematic representation of the 1-D calculation space.

was reversibly absorbed by the foil. ${ }^{19}$ This resulted in an initial boundary temperature of approximately $1500 \mathrm{~K}$, which is in line with previous studies. $^{4-8}$

The variation of thermal properties (density, thermal conductivity and heat capacity) with temperature was handled by fitting literature data ${ }^{11-13,20-28}$ for the properties in the Sn-Zn alloy system. This fit was accomplished using a phenomenological regular solution model that utilized the Redlich-Kister polynomial (Eq. 3) ${ }^{29}$ In the equation below, $P, P_{1}, P_{2}, X_{1}, T$ and $L_{i}$ represent the generic property of interest (i.e. thermal conductivity or density), property of component 1 , property of component 2 , atomic fraction of component 1 , absolute temperature $(\mathrm{K})$ and interaction parameter, respectively.

$$
\begin{aligned}
P\left(X_{1}, T\right)= & X_{1} P_{1}(T)+\left(1-X_{1}\right) P_{2}(T) \\
& +X_{1}\left(1-X_{1}\right) \sum_{i=0}^{n} L_{i}\left(2 X_{1}-1\right)^{i}
\end{aligned}
$$

Examples of the regular solution model fits for thermal conductivity and density for Sn-Zn liquid solutions, over multiple compositions and a range of temperatures, are given in Fig. 2.

The equations that describe the fit to the literature data are also presented (Eqs. 4-6). In these equations, $X_{\mathrm{Zn}}, T, k$, and $\rho$ are the atomic fraction of $\mathrm{Zn}$, absolute temperature, thermal conductivity $(\mathrm{W} / \mathrm{m}-\mathrm{K})$ and density $\left(\mathrm{kg} / \mathrm{m}^{3}\right)$, respectively. The values for thermal conductivity in the solid state for each of the experimental alloys was taken from the literature $(85.7 \mathrm{~W} / \mathrm{m}-\mathrm{K}$ and $97.3 \mathrm{~W} / \mathrm{m}-\mathrm{K}$ for $14 \mathrm{Zn}$ and $50 \mathrm{Zn}$, respectively $)^{11}$ and were held constant as a function of temperature during the calculation. This was due to the limited temperature range over which the alloys were in the solid state, which results in negligible changes in the final calculation of HAZ size.

Sn-Zn liquid phase temperature- and composition-dependent thermal conductivity, $k\left(X_{\mathrm{Zn}}, T\right)$ :

$$
\begin{aligned}
k\left(X_{\mathrm{Zn}}, T\right)= & X_{\mathrm{Zn}}\left(2.7 \times 10^{-2} T+36.4\right)+\left(1-X_{\mathrm{Zn}}\right) \\
& \times\left(2.2 \times 10^{-2} T+19.2\right)+(-16.2) \\
& \times\left(X_{\mathrm{Zn}}-X^{2}\right)+(-10.0) \\
& \times\left(X_{\mathrm{Zn}}-X_{\mathrm{Zn}}^{2}\right)\left(2 X_{\mathrm{Zn}}-1\right)
\end{aligned}
$$

Sn-Zn solid phase temperature- and compositiondependent density, $\rho_{\text {solid }}\left(X_{\mathrm{Zn}}, T\right)$ :

$$
\begin{aligned}
\rho_{\text {solid }}\left(X_{\mathrm{Zn}}, T\right)= & X_{\mathrm{Zn}}\left(7140 \exp \left(-3.27 \times 10^{-5}(T-300)\right)\right. \\
& +\left(1-X_{\mathrm{Zn}}\right)\left(7 2 6 0 \operatorname { e x p } \left(-5.43 \times 10^{-5}\right.\right. \\
& \times(T-300)))+(2181.0-4.1 T)\left(X_{\mathrm{Zn}}-X_{\mathrm{Zn}}^{2}\right)
\end{aligned}
$$

Sn-Zn liquid phase temperature- and compositiondependent density, $\rho_{\text {liquid }}\left(X_{\mathrm{Zn}}, T\right)$ :

$$
\begin{aligned}
\rho_{\text {liquid }}\left(X_{\mathrm{Zn}}, T\right)= & X_{\mathrm{Zn}}\left(6575 \exp \left(-1.34 \times 10^{-4}(T-693)\right)\right) \\
& +\left(1-X_{\mathrm{Zn}}\right)\left(6 9 8 0 \operatorname { e x p } \left(-1.01 \times 10^{-4}\right.\right. \\
& \times(T-505)))+(232.3-0.8 T) \\
& \times\left(X_{\mathrm{Zn}}-X_{\mathrm{Zn}}^{2}\right)+(-1203.0+0.7 T) \\
& \times\left(X_{\mathrm{Zn}}-X_{\mathrm{Zn}}^{2}\right)\left(2 X_{\mathrm{Zn}}-1\right)
\end{aligned}
$$

In order to account for melting in the substrate, values for transition temperatures and $\Delta H_{\text {fus }}$ were obtained from DSC experiments. It was assumed that the HAZ size would correspond to the maximum distance into the substrate that the liquidus temperature ( $\left.T_{\text {liquidus }}\right)$ was reached. Although the HAZ can extend beyond the region where melting occurs, this assumption was based on the limited time for mass transport due to the extremely short timescales $(<400 \mathrm{~ms})^{4}$ that the samples were expected to be at elevated temperatures.

From previous work, ${ }^{16}$ it was found that there was a large variability of the observed HAZ size. This was attributed to the tendency for the foil to distort significantly during the reaction, which functionally increased the thermal interfacial resistance between the foil and substrate, and resulted in uneven heat flow into the substrate alloys. The effect of the foil distortion was accounted for in the 1-D calculations by varying the initial boundary temperature and determining an average HAZ size over multiple simulations.

In order to parameterize the model with microstructural features, a two-dimensional (2-D) numerical calculation was performed using a finite difference approximation of the $2-\mathrm{D}$ heat equation.

$$
\frac{\partial T}{\partial t}=\alpha\left(\frac{\partial^{2} T}{\partial x^{2}}+\frac{\partial^{2} T}{\partial y^{2}}\right)
$$



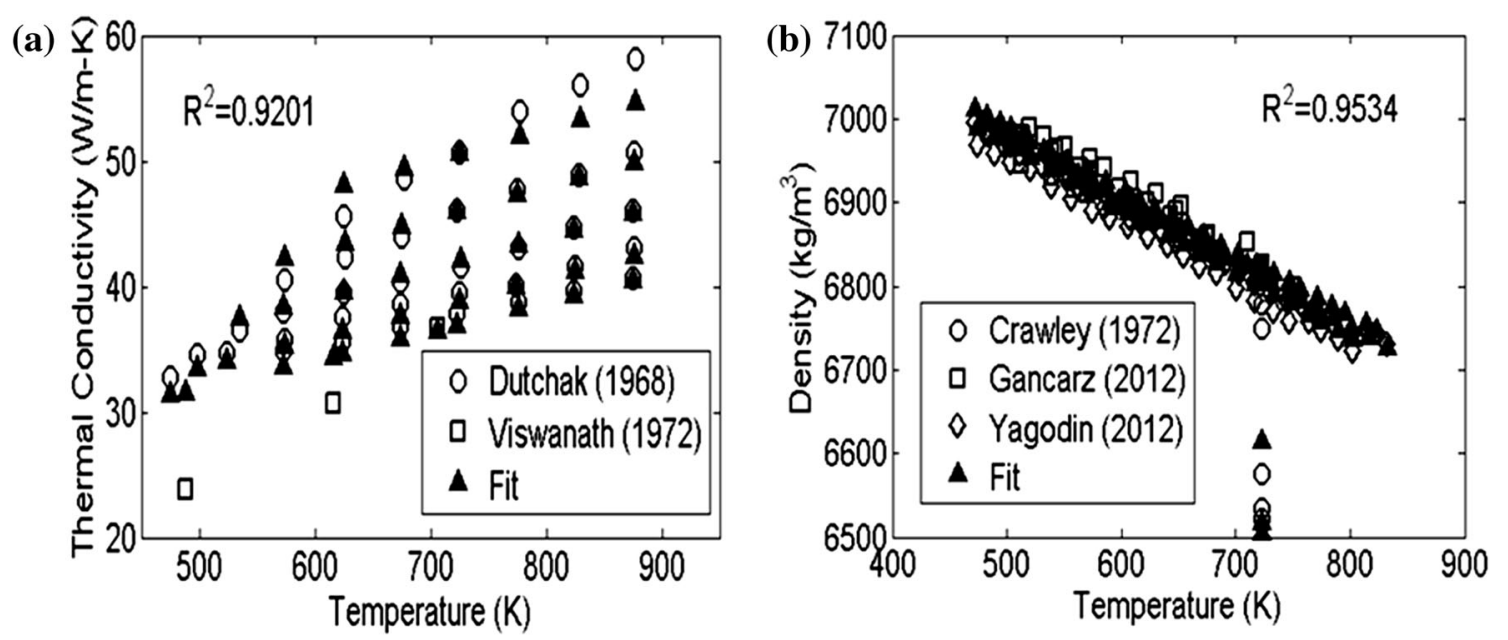

Fig. 2. Regular solution model fits (closed markers) of experimental data from literature (open symbols) for (a) thermal conductivity ${ }^{26,27}$ and (b) density ${ }^{20,21,23}$ of liquid Sn-Zn alloys.

Table I. Experimental alloy compositions determined using XRF: Nominal (Measured \pm 1 standard deviation)

\begin{tabular}{|c|c|c|c|}
\hline Alloy designation & \multicolumn{3}{|c|}{ Composition } \\
\hline $50 \mathrm{Zn}$ & bal. & $50.0(54.8 \pm 1.9)$ & $64.5(68.7 \pm 1.7)$ \\
\hline
\end{tabular}

Microstructural features were included by digitizing SEM micrographs taken from a Sn-50 wt.\% $\mathrm{Zn}$ alloy. This alloy was used because its coarse microstructure allowed for a representative digital microstructure to be created using the same node size as the 1-D model $(5 \mu \mathrm{m})$. The thermal properties of the each phase in the microstructure were assigned to the digital microstructure that formed the calculation space. The predictions of both calculations were compared to the observed HAZ sizes and their respective efficacies discussed.

\section{RESULTS AND DISCUSSION}

\section{Compositional and Calorimetric Analysis}

The results from the compositional analysis performed using XRF are presented in Table I.

Representative DSC heating curves for both of the alloys are presented in Fig. 3. Both alloys exhibited the expected behavior based on the published phase diagram. ${ }^{10}$ The values for the solidus $\left(T_{\text {solidus }}\right)$ and liquidus ( $T_{\text {liquidus }}$ ) temperatures, along with $\Delta \mathrm{H}_{\text {fus }}$, are enumerated in Table II.

\section{Microstructure Evolution}

The as-cast microstructure for both alloys (Fig. 4) consisted of elongated pro-eutectic Zn phases surrounded by an interconnected eutectic structure.
Within the post-reaction microstructure, a HAZ was observed extending out from the RMF-substrate interface (Fig. 5). Beyond the HAZ boundary, the bulk microstructure remained unchanged from the as-cast morphology.

Figure 5 illustrates the differences observed, at higher resolution, between the bulk and HAZ microstructures. In the 14Zn alloy (Fig. 6a and b), the HAZ consists of a relatively homogeneous distribution of globular particles. It is known that the increase in cooling rate increases the solidification front velocity in the alloy. ${ }^{30}$ As the solidification front velocity increases, the partition coefficient approaches a value of 1 , which results in a more homogeneous microstructure. ${ }^{31}$ Under equilibrium conditions, the partition coefficient in this region of the $\mathrm{Sn}-\mathrm{Zn}$ phase diagram is 0 , which indicates a tendency for Sn to partition away from the pro-eutectic Zn phase. Additionally, the enthalpy of mixing for $\mathrm{Zn}$ and $\mathrm{Sn}$ is positive over the entire composition regime ${ }^{32,33}$ which contributes to the lenticular shape of the pro-eutectic $\mathrm{Zn}$ phase observed in the $14 Z n$ alloy.

In the 50Zn alloy (Fig. 6c and d), the microstructure transitions from that consisting of coarse, proeutectic $\mathrm{Zn}$ dendrites surrounded by eutectic into a more refined dendritic structure surrounded by what appears to be a more divorced eutectic structure. 
The existence of dendrite arms in both the bulk and HAZ microstructures in the 50Zn alloy allowed for the measurement of dendrite-arm spacing (SDS), which can be correlated to relative solidification rates. $^{34,35}$ By measuring the SDS, the solidification rates experienced by the two microstructures were compared using Eq. 8.

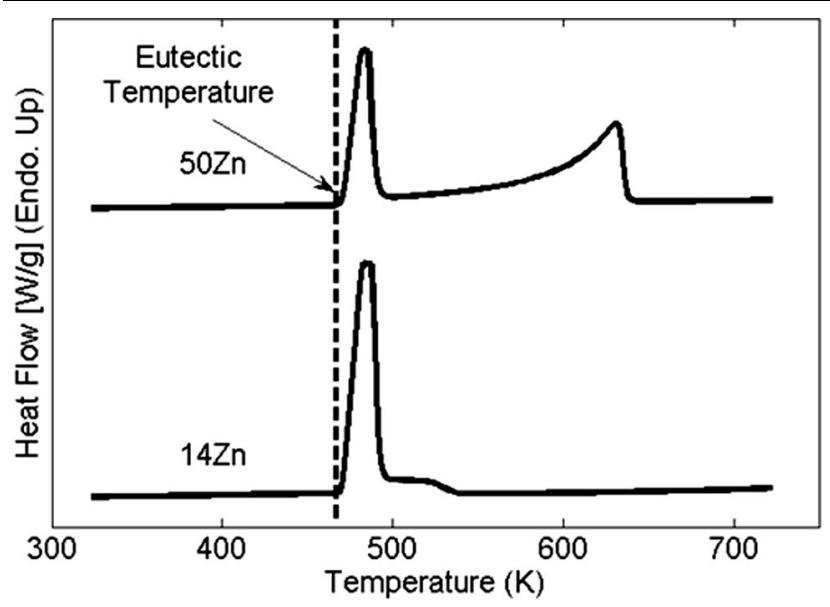

Fig. 3. DSC heating curves, from the second heating cycle, for the experimental $\mathrm{Sn}-\mathrm{Zn}$ alloys. The peaks represent endothermic reactions, specifically melting. Each of the curves has been normalized by the sample mass to enable direct comparison.

$$
\lambda_{\mathrm{SDS}}^{3}=C t
$$

SDS is represented by $\lambda_{\mathrm{SDS}}, t$ is the solidification time (i.e. the time it takes for the temperature to decrease from $T_{\text {liquidus }}$ to $T_{\text {solidus }}$ ) of the alloy and $C$ is a constant. The value for SDS in the cast alloy was observed to be $7.1 \pm 0.8 \mu \mathrm{m}$ and in the HAZ it was found to be $0.7 \pm 0.2 \mu \mathrm{m}$. Using these values, the average solidification rate in the $\mathrm{HAZ}$ was determined to be approximately three orders of magnitude greater than the average as-cast solidification rate (see Table III).

\section{1-D Model Results: Microstructure Invariant}

When the experimental HAZ sizes were compared to the 1-D model calculation, a discrepancy was observed (Fig. 6). The predicted HAZ sizes were approximately a factor of two greater than the observed sizes. This was attributed to the difference in thermal conductivity between the pro-eutectic $\mathrm{Zn}$ relative to the bulk alloy, which was also approximately a factor of two. The difference in properties allows for the pro-eutectic to be a more efficient path for energy transport, based on Fourier's law, ${ }^{15}$ effectively making it a "short-circuit" pathway within the microstructure. Additionally, this effect could be magnified by the large melting range of the

Table II. Experimental values for transition temperatures and enthalpy of fusion for the experimental alloys used in the 1-D model

\begin{tabular}{|c|c|c|c|}
\hline Alloy & $\mathbf{T}_{\text {solidus }}(\mathbf{K})$ & $\mathbf{T}_{\text {liquidus }}(\mathbf{K})$ & $\Delta \mathrm{H}_{\text {fus }}(\mathrm{J} / \mathrm{g})$ \\
\hline $14 \mathrm{Zn}$ & $469.9 \pm 0.1$ & $532.9 \pm 6.4$ & $77.7 \pm 0.3$ \\
\hline $50 \mathrm{Zn}$ & $470.1 \pm 0.3$ & $637.4 \pm 0.2$ & $117.2 \pm 0.2$ \\
\hline
\end{tabular}

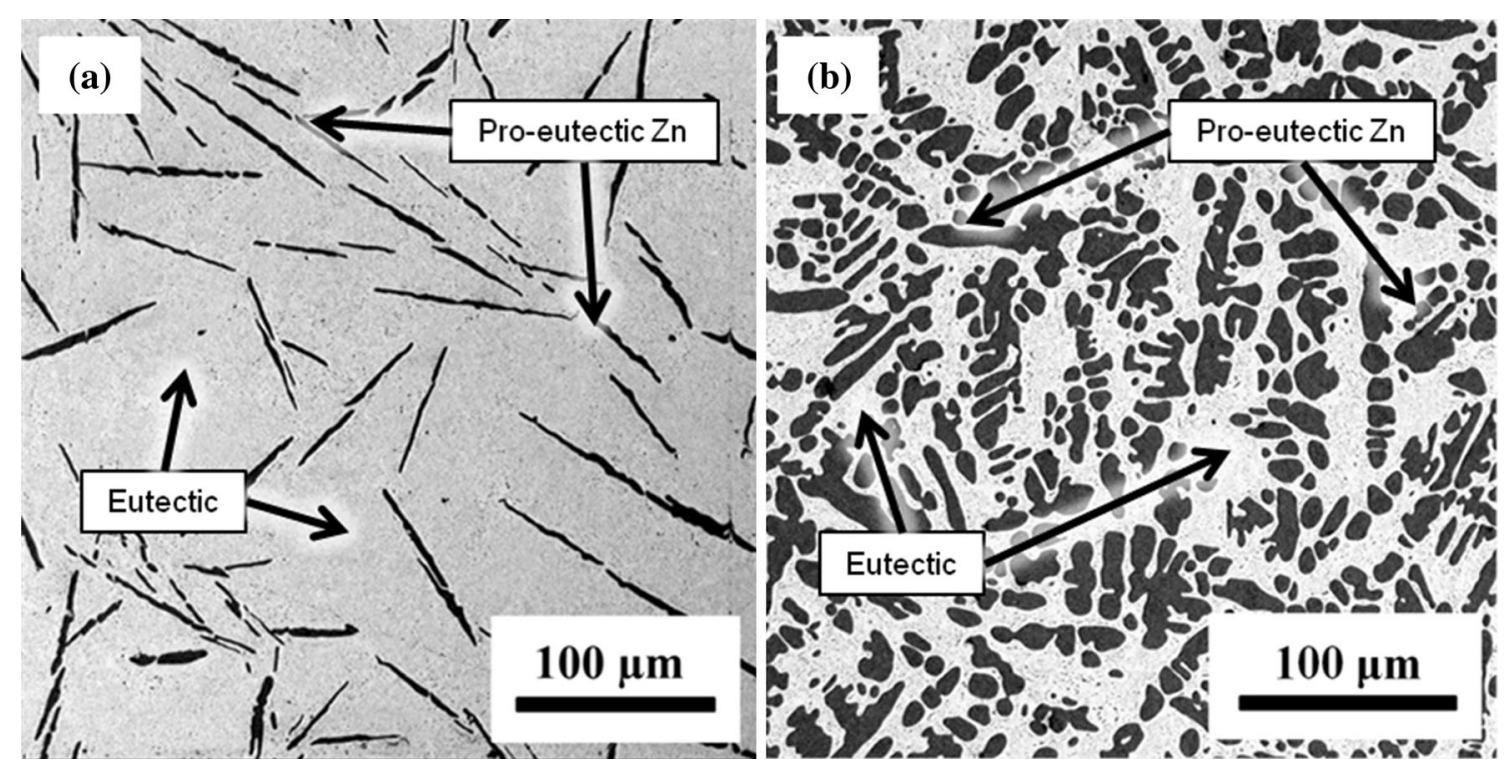

Fig. 4. Backscattered electron micrographs of (a) $14 \mathrm{Zn}$ and (b) $50 \mathrm{Zn}$ in the as-cast condition. 

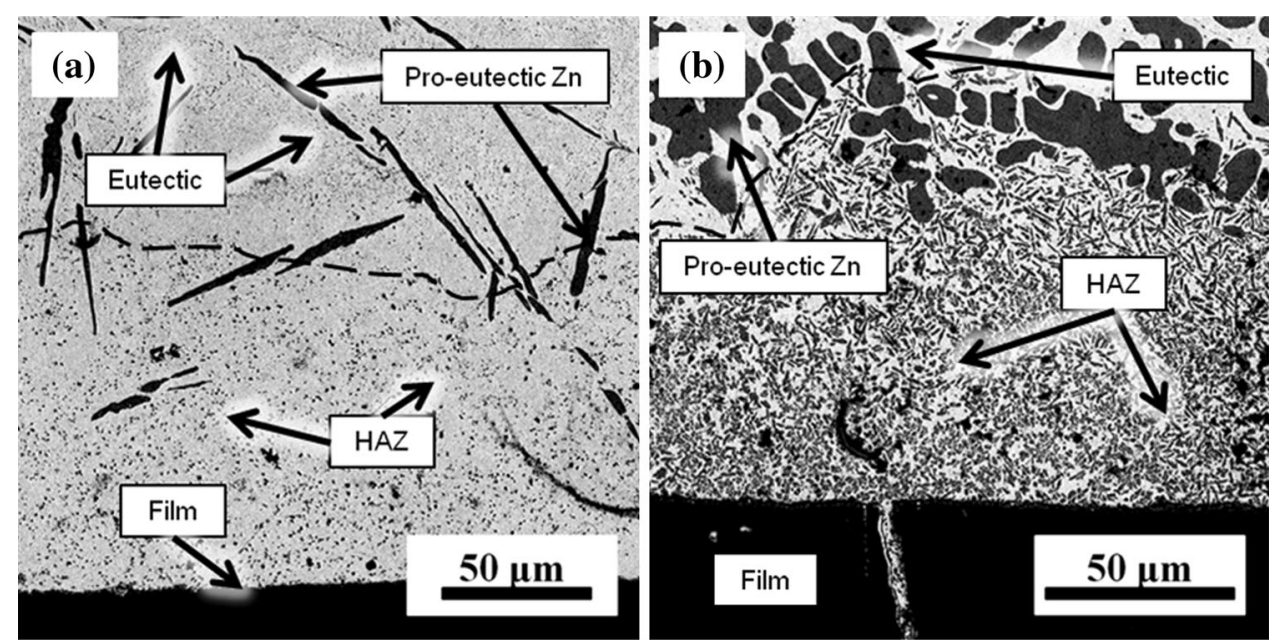

Fig. 5. Backscattered electron micrographs of the HAZ microstructure in (a) $14 \mathrm{Zn}$ and (b) $50 \mathrm{Zn}$. The dashed line in (a) indicates the HAZ boundary.
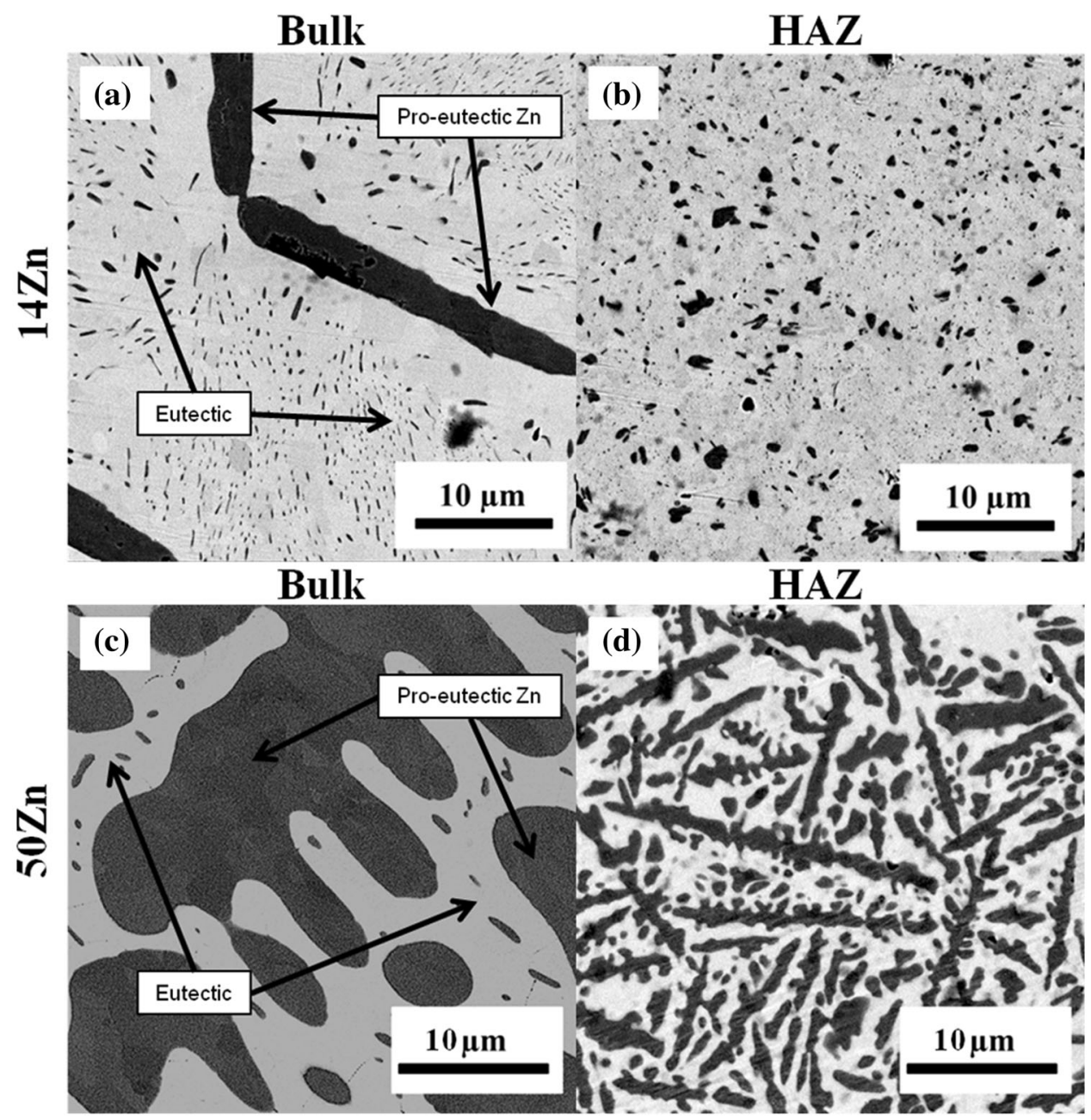

Fig. 6. Back-scattered electron micrographs comparing the (a) unreacted microstructure of $14 \mathrm{Zn}$, (b) the HAZ microstructure of $14 \mathrm{Zn}$, (c) the unreacted microstructure of $50 \mathrm{Zn}$ and (d) the HAZ microstructure of $50 \mathrm{Zn}$. 
Table III. Comparison of the relative solidification rates between the bulk and HAZ in $50 \mathrm{Zn}$ calculated using the microstructure and model

\begin{tabular}{|c|c|c|c|}
\hline Method & Bulk & HAZ & HAZ solidification rate/bulk solidification rate \\
\hline Microstructure (SDS) & $7.1 \pm 0.8 \mu \mathrm{m}$ & $0.7 \pm 0.2 \mu \mathrm{m}$ & 1043 \\
\hline Model & $21.8 \mathrm{~K} / \mathrm{s}$ & $24000.0 \mathrm{~K} / \mathrm{s}^{\mathrm{a}}$ & 1100 \\
\hline
\end{tabular}

${ }^{\mathrm{a}}$ Microstructure contributions included (mean \pm 1 standard deviation).

alloys, as this would allow for the pro-eutectic phase to persist for longer in the structure. This local heat transport effect is not accounted for in the model, leading as a result to an improper estimate of HAZ scale.

To include the effect of microstructure, the calculation of liquid thermal conductivity in the melting range was modified, by a factor of two, to include the contributions of a persistent pro-eutectic phase in the HAZ. Then, the simulations were run again. As a result of the modification, the predicted values were then brought closer to the experimentally observed values (Fig. 7). Figure 8 gives an example of the evolution of temperature as a function of time within the substrate, which can be used to extract cooling rates within the HAZ.

To further validate the efficacy of the model predictions, the solidification rate within the HAZ was extracted and compared to the average solidification rate experienced by the bulk microstructure, which was calculated based on the casting conditions, alloy and copper mold properties (Table III). When the average solidification rate of the $\mathrm{HAZ}$ region was normalized by the average solidification rate from the casting of the $50 \mathrm{Zn}$ alloy, the result was approximately a three orders of magnitude difference between the two conditions, which closely matches the relative solidification rate difference determined using the SDS measurements in the $50 \mathrm{Zn}$ alloy. These experimental observations helps to validate the model predictions and to reinforce the need to include microstructural features into the model in order to accurately simulate the behavior of the system.

\section{2-D Model Results: Microstructurally- Informed}

A microstructurally-informed model necessitated an expansion to 2-D to account for thermal transport into different phase regions. Prior to an attempt to model a representative microstructure being undertaken, a simplified microstructure containing a single dendrite was simulated. This simplified structure allowed for the evaluation of the hypothesis that the $\mathrm{Zn}$ pro-eutectic dendrites could act as a "short-circuit" path for heat transport in the microstructure. If this was in fact the case, it was expected that melting of the eutectic would initiate

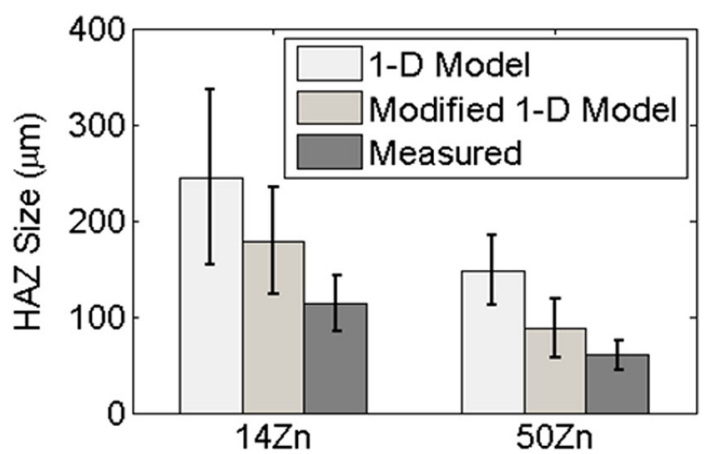

Fig. 7. Comparison of the predicted $H A Z$ size using the 1-D model with an enhanced liquid thermal conductivity to account for un-melted $\mathrm{Zn}$ contributions to heat transport and the experimentally measured HAZ in the two Sn-Zn alloys.

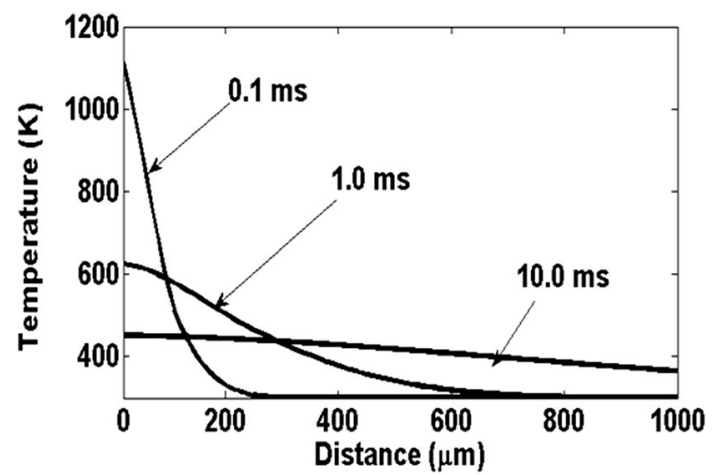

Fig. 8. The temperature profile within the substrate at different time steps. Calculated for the 50Zn alloy.

at the dendrite-eutectic interface as there would be a larger amount of energy available when compared to the bulk eutectic.

The microstructure was created in MATLAB ${ }^{\circledR}$ by using a matrix with nodes in the shape of a dendrite assigned the number 1 with all the remaining nodes in the calculation space being given the value of 0 (in this case 1 represented the pro-eutectic phase and 0 corresponded to the eutectic phase). For the simulation, each of the microstructure constituents was assigned unique physical properties (density, thermal conductivity and heat capacity) that were calculated based on literature values. The values for $\Delta \mathrm{H}_{\text {fus }}$ for the respective phases were also taken from the literature. ${ }^{18,36}$ To reduce computational 
Table IV. Materials properties from the 2-D simulation ${ }^{13,18,20,27,36}$

\begin{tabular}{|c|c|c|c|}
\hline \multirow[b]{2}{*}{ Parameter } & \multicolumn{3}{|c|}{ Constituent/phase } \\
\hline & Eutectic (solid, liquid) & Solid Zn & Liquid 50Zn \\
\hline$k(\mathrm{~W} / \mathrm{m}-\mathrm{k})$ & $80.1,32.2$ & 113.0 & 44.1 \\
\hline$\rho\left(\mathrm{kg} / \mathrm{m}^{3}\right)$ & $7363.0,7031.0$ & 7140.0 & 6543.0 \\
\hline$C p(\mathrm{~J} / \mathrm{kg}-\mathrm{K})$ & $242.0,276.0$ & 388.0 & 370.0 \\
\hline$\Delta H_{\text {fus }}(\mathrm{J} / \mathrm{kg})$ & $75.0 \times 10^{3}$ & $111.4 \times 10^{3}$ & - \\
\hline
\end{tabular}
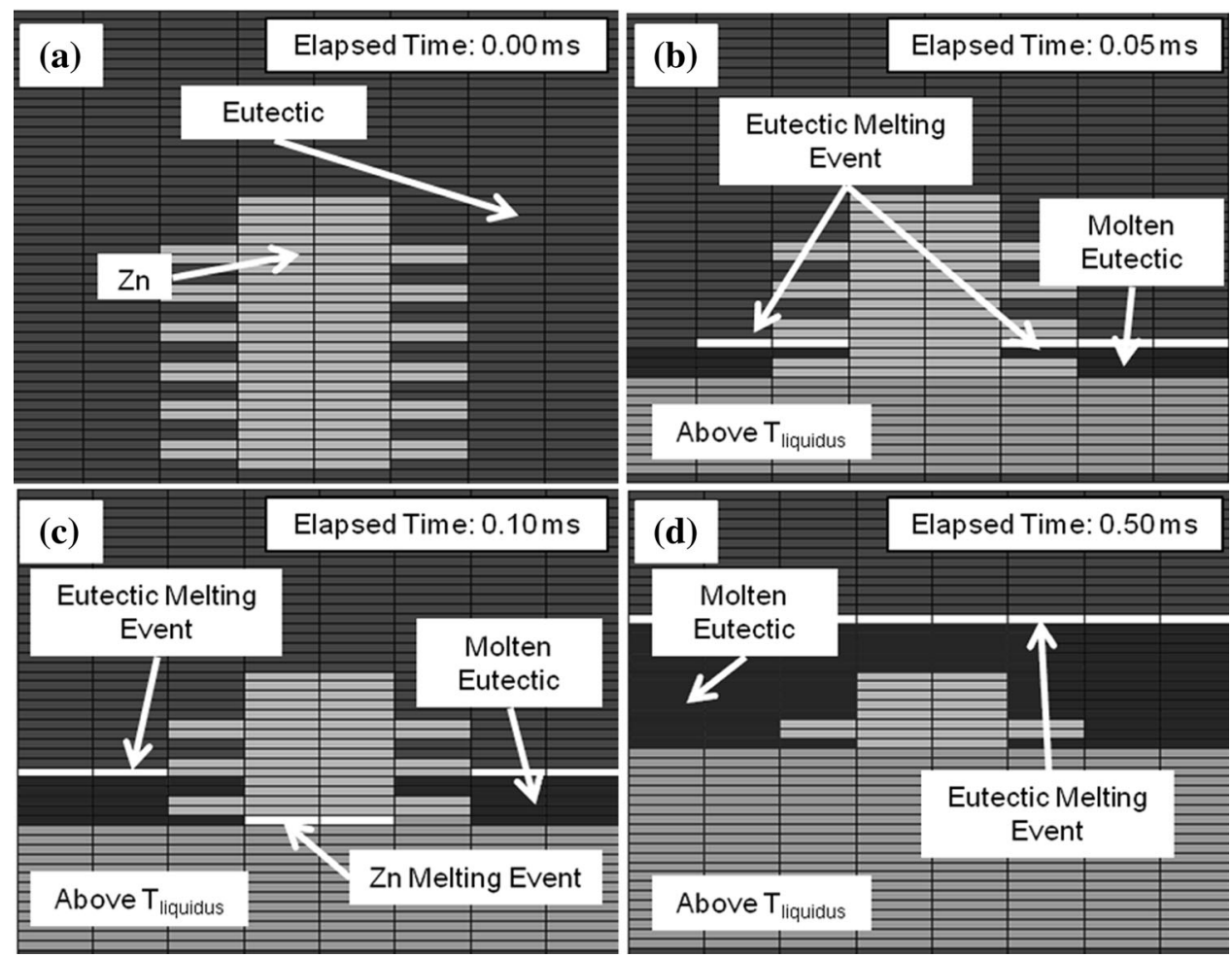

Fig. 9. Heat capacity maps of the single dendrite microstructure to show the progression of the melting front as heat is conducted into the substrate at (a) $0.00 \mathrm{~ms}$, (b) $0.05 \mathrm{~ms}$, (c) $0.10 \mathrm{~ms}$ and (d) $0.50 \mathrm{~ms}$. (The white nodes are undergoing a solid $\leftrightarrow$ liquid phase transformation) Note: the nodes are $5 \mu \mathrm{m} \times 5 \mu \mathrm{m}$. The nodes appear rectangular due to the scaling of the images, which are small sections of a much larger calculation space.

intensity, the physical properties of the respective constituents were held constant with respect to temperature. The properties would only change if a node underwent a phase transformation (i.e. melting). The values used in the 2 -D calculation are presented in Table IV.

During the simulation, the respective microstructural features retained their distinct properties. Eutectic nodes were allowed to melt at the eutectic temperature $(469 \mathrm{~K})$, at which point the properties of the node changed to those of the liquid eutectic. Proeutectic $\mathrm{Zn}$ nodes retained the properties of the solid until the node temperature reached $T_{\text {liquidus }}$, at which it would take on the bulk properties of the liquid alloy at the melting temperature for all subsequent temperatures, regardless of its origin as a pro-eutectic $\mathrm{Zn}$ or eutectic constituent. This gives an approximation of the local conditions in the alloy, since the liquid is predicted to be uniform above $T_{\text {liquidus }}{ }^{10}$

To properly visualize phase transformations during the simulation, heat capacity maps were used because they could clearly illustrate the phases present in the microstructure. The evolution of the microstructure as a function of time is presented in Fig. 9 (note: the node size is $5 \mu \mathrm{m} \times 5 \mu \mathrm{m}$ ). The different colors in the images correspond to different heat capacity values, which are related to the respective phases present. Since there are two distinct melting events that can occur during the simulation, eutectic melting and complete melting (labeled "Above $T_{\text {liquidus }}$ "), two distinct colors were used to represent these events (note: this color 
scheme is consistent between Figs. 9 and 11). Results from the simulation supported the hypothesis by demonstrating that eutectic melting initiated at the dendrite (Fig. 9b) then progressed outward, away from the interface. The simulation also highlights how melting of the eutectic can occur deeper in the substrate than complete melting of the alloy (Fig. 9d).

In order to include the complexity of a real microstructure into the simulation, a representative micrograph of $50 \mathrm{Zn}$ was used (Fig. 10a). The image was first converted to a binary image (black and white) using the ImageJ software program (Fig. 10b). This processed image was then digitized in MATLAB ${ }^{\circledR}$ by assigning a 1 to pixels that were black and 0 to white pixels, which identified the microstructure constituent. The node size was chosen to be $5 \mu \mathrm{m} \times 5 \mu \mathrm{m}$ (the same resolution as the 1-D model). This was achieved by averaging the values of the pixels that were contained within the individual node areas. If the value was $>0.5$, it was considered to be mostly pro-eutectic $\mathrm{Zn}$ and the node assigned a value of 1 ; values $<0.5$ were considered mostly eutectic and were assigned a value of 0 . The resultant digital microstructure was a coarser, although representative, version of the original microstructure (Fig. 10c).

Simulations were then run using these complex microstructures. Representative heat capacity maps, taken from different times during the simulation, are presented in Fig. 11. Although it is not readily obvious when looking at the static images, the simulation demonstrated that eutectic melting is initiated at nodes adjacent to the pro-eutectic $\mathrm{Zn}$ phases (Fig. 11b), similar to the effect observed in Fig. 9. The melting would then continue out to the edge of the calculation space before the melting front progressed further into the substrate. This again supports the idea that the $\mathrm{Zn}$ could act as a local "short-circuit" pathway for heat. Since the heat from the RMF reaction is more readily transported along the dendrite than through the eutectic, there is more heat available locally to the dendrite to melt the eutectic than there would be in regions further away. As a result, the simulation again captured how the melting front in the eutectic can precede the front where the entire structure is molten (Fig. 11c).

The predicted HAZ size, based on the 2-D calculation, ranged between 90 and $100 \mu \mathrm{m}$. Although this simulation could not predict the exact HAZ size (observed HAZ $60 \pm 15 \mu \mathrm{m}$ ), the predicted value is much closer to the experimentally observed value than the 1-D model which ignored the microstructure $(148 \pm 36 \mu \mathrm{m})$. It may be possible to further improve the agreement between the predictions and experiments by including factors such as the error due to foil undulation, temperature-dependent physical properties of the phases or by decreasing

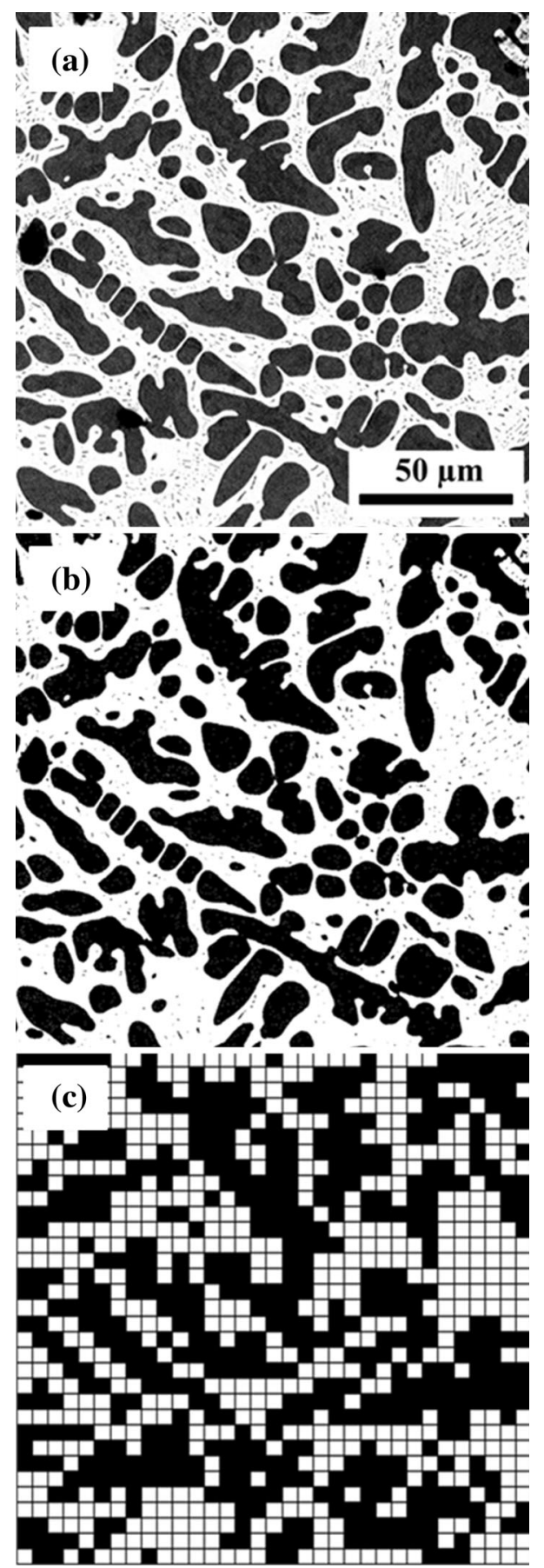

Fig. 10. Addition of microstructural features to the calculation. (a) The original backscattered electron image, (b) the microstructure image converted to black and white using ImageJ software and (c) the node mesh created based on the SEM image in MATLAB ${ }^{\circledR}$ (Note: all of the images are on the same scale).

the node size in order to improve the overall resolution of the 2-D model. However, the 2-D model did validate the need to account for microstructure effects when attempting to predict the scale of a HAZ that is the result of a RMF reaction. 

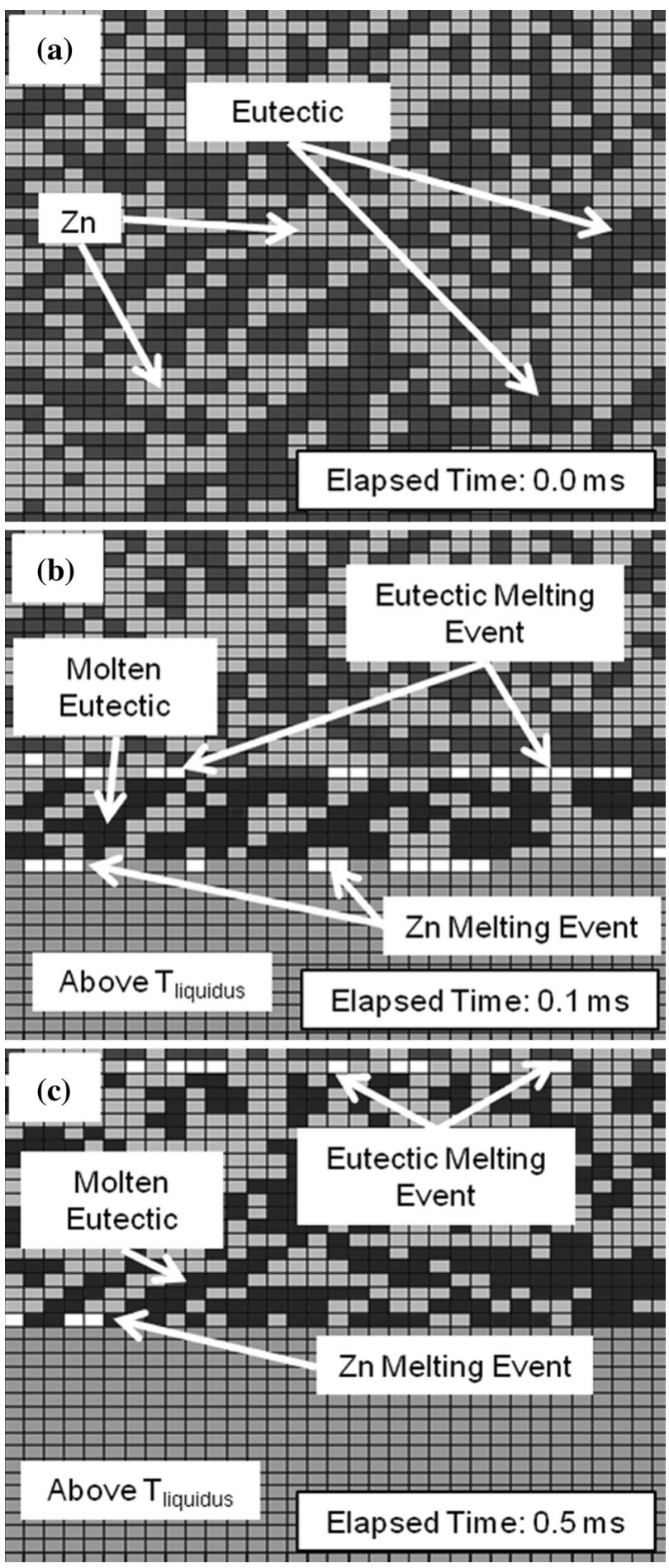

Fig. 11. Heat capacity maps of digitized microstructure to show the progression of the melting front as heat is conducted into the substrate at (a) $0.0 \mathrm{~ms}$, (b) $0.1 \mathrm{~ms}$ and (c) $0.5 \mathrm{~ms}$. The white nodes are undergoing a solid $\leftrightarrow$ liquid phase transformation (Note: the nodes are $5 \mu \mathrm{m} \times 5 \mu \mathrm{m})$.

\section{CONCLUSIONS}

This work explored the microstructural evolution that occurred in two Sn-Zn alloys as a result of the reaction of a neighboring $\mathrm{Ni}(\mathrm{V})-\mathrm{Al} \mathrm{RMF}$ heat source. The extreme local temperatures caused melting in the alloys and the rapid cooling conditions resulted in a highly refined, more homogeneous microstructure in the HAZ, compared to the bulk. In the $50 \mathrm{Zn}$ alloy, the difference in the SDS measured in the bulk and HAZ microstructures indicated that the HAZ microstructure experiences a cooling rate that was approximately three orders of magnitude faster than the bulk during casting.

When a 1-D model that did not include microstructure (i.e. microstructure-invariant) was used to predict the scale of the HAZ, it was found to overestimate the measured value by approximately a factor of two. This difference corresponded well to the difference in thermal conductivity between the pro-eutectic $\mathrm{Zn}$ and the bulk alloy. When this mechanism was accounted for in the model, the predicted values fell much closer to the experimental observations. Additionally, when the solidification rate predicted by the model was compared to the solidification rate calculated for the casting conditions of the $50 \mathrm{Zn}$ alloy, the relative difference was approximately three orders of magnitude, the same as was determined based on the microstructure observations. This validated the model predictions and reinforced the need for the microstructure to be considered in the model.

A 2-D model was then created, which accounted for the microstructure by digitizing a representative micrograph of the 50Zn alloy. This methodology predicted a HAZ size of $90-100 \mu \mathrm{m}$, which is closer to the observed value $(60 \pm 15 \mu \mathrm{m})$ than the original 1-D model $(148 \pm 36 \mu \mathrm{m})$. The results of this work indicate that the initial substrate microstructure can play a large role in the heat flow, and, consequently, the microstructure evolution that results from RMF reactions. Therefore, it should in future be accounted for in examinations of these reactions.

\section{ACKNOWLEDGEMENTS}

This work was supported by the Sandia Campus Executive Fellowship. Sandia National Laboratories is a multi-program laboratory managed and operated by Sandia Corporation, a wholly owned subsidiary of Lockheed Martin Company, for the United States Department of Energy's National Nuclear Security Administration under Contract DE-AC04-94AL85000.

\section{OPEN ACCESS}

This article is distributed under the terms of the Creative Commons Attribution 4.0 International License (http://creativecommons.org/licenses/by/4.0/), which permits unrestricted use, distribution, and reproduction in any medium, provided you give appropriate credit to the original author(s) and the source, provide a link to the Creative Commons license, and indicate if changes were made. 


\section{REFERENCES}

1. D.P. Adams, Thin Solid Films 576, 98 (2015).

2. A. Duckham, S.J. Spey, J. Wang, M.E. Reiss, T.P. Weihs, E. Besnoin, and O.M. Knio, J. Appl. Phys. 96, 2336 (2004).

3. E. Besnoin, O. Knio, T. P. Weihs, and J. Wang, Nanostructured Soldered or Brazed Joints Made with Reactive Multilayer Foils, EP1631450B1, 2007.

4. J. Wang, E. Besnoin, A. Duckham, S.J. Spey, M.E. Reiss, O.M. Knio, and T.P. Weihs, J. Appl. Phys. 95, 248 (2004).

5. J. Wang, E. Besnoin, O.M. Knio, and T.P. Weihs, J. Appl. Phys. 97, 114307 (2005).

6. J. Wang, E. Besnoin, A. Duckham, S.J. Spey, M.E. Reiss, O.M. Knio, M. Powers, M. Whitener, and T.P. Weihs, Appl. Phys. Lett. 83, 3987 (2003).

7. J. Wang, E. Besnoin, O.M. Knio, and T.P. Weihs, Acta Mater. 52, 5265 (2004).

8. A.J. Swiston, E. Besnoin, A. Duckham, O.M. Knio, T.P. Weihs, and T.C. Hufnagel, Acta Mater. 53, 3713 (2005).

9. P. Peng, A. Hu, H. Huang, A.P. Gerlich, B. Zhao, and Y.N. Zhou, J. Mater. Chem. 22, 12997 (2012).

10. H. Okamoto, Desk Handbook: Phase Diagrams for Binary Alloys, 2nd ed. (Materials Park, Ohio: ASM International, 2010).

11. F. Meydaneri, B. Saatçi, M. Gündüz, and M. Özdemir, Contin. Mech. Thermodyn. 25, 691 (2012).

12. K. Matsugi, G. Sasaki, O. Yanagisawa, Y. Kumagai, and K. Fujii, Mater. Trans. 48, 1105 (2007).

13. B. Saatçi, N. Maraşl1, and M. Gündüz, Thermochim. Acta 454, 128 (2007).

14. M.G. Cooper, B.B. Mikic, and M.M. Yovanovich, Int. J. Heat Mass Transf. 12, 279 (1969).

15. D.R. Poirier and G.H. Geiger, Transport Phenomena in Materials Processing (Warrendale, PA: The Minerals, Metals \& Materials Society, 1994).
16. R.J. Hooper, C.G. Davis, P.M. Johns, D.P. Adams, D. Hirschfeld, J.C. Nino, and M.V. Manuel, J. Appl. Phys. (2015). doi:10.1063/1.4922981.

17. C. Michaelsen, K. Barmak, and T.P. Weihs, J. Phys. D Appl. Phys. 30, 3167 (1997).

18. C.J. Smithells, W.F. Gale, and T.C. Totemeier, Smithells Metals Reference Book, 8th ed. (Amsterdam; Boston: Elsevier Butterworth-Heinemann, 2004).

19. R.T. DeHoff, Thermodynamics in Materials Science, 2nd ed. (Boca Raton: CRC/Taylor \& Francis, 2006).

20. D. Yagodin, V. Sidorov, D. Janickovic, and P. Svec, J. NonCryst. Solids 358, 2935 (2012).

21. A.F. Crawley, Metall. Trans. 3, 971 (1972).

22. T. Gancarz, W. Gąsior, and H. Henein, Int. J. Thermophys. 34, 250 (2013)

23. T. Gancarz, J. Pstrus, W. Gasior, and H. Henein, J. Electron. Mater. 42, 288 (2012).

24. S.D. Veazey and W.C. Roe, J. Mater. Sci. 7, 445 (1972).

25. M.J. Assael, I.J. Armyra, J. Brillo, S.V. Stankus, J. Wu, and W.A. Wakeham, J. Phys. Chem. Ref. Data 41, 033101 (2012).

26. D.S. Viswanath and B.C. Mathur, Metall. Trans. 3, 1769 (1972).

27. Y.I. Dutchak, V.P. Osipenko, P.V. Panasyuk, and O.P. Stetskiv, Ukr. J. Phys. 13, 695 (1968).

28. S. Kim, K.-S. Kim, S.-S. Kim, and K. Suganuma, J. Electron. Mater. 38, 266 (2008)

29. O. Redlich and A.T. Kister, Ind. Eng. Chem. 40, 345 (1948).

30. E.J. Lavernia, J.D. Ayers, and T.S. Srivatsan, Int. Mater. Rev. 37, 1 (1992).

31. M. Carrard, M. Gremaud, M. Zimmermann, and W. Kurz, Acta Metall. Mater. 40, 983 (1992)

32. O.J. Kleppa, J. Phys. Chem. 59, 354 (1955)

33. B.J. Lee, $C A L P H A D$ 20, 471 (1996).

34. D.H. Kirkwood, Mater. Sci. Eng. 73, L1 (1985).

35. N. Tunca and W.R. Smith, J. Mater. Sci. 23, 111 (1988).

36. J. Song, N. Liu, and K. Lin, Mater. Trans. 45, 776 (2004). 